\title{
COMPARISON OF CATECHOLAMINE AND PRESSOR EFFECTS IN PERIBULBAR AND RETROBULBAR ANAESTHESIA IN CATARACT SURGERY
}

\author{
R. SANDERS, S. AHMED, E. W. CRAIG and J. D. H. YOUNG \\ Dundee
}

\begin{abstract}
SUMMARY
Peribulbar anaesthesia is now established as an alternative to retrobulbar anaesthesia for cataract surgery. However, the larger volume of anaesthetic solution in the extraconal orbit with the peribulbar technique might carry a higher risk of systemic side-effects. To assess this risk we carried out a prospective randomised comparison of plasma catecholamine and pressor effects between the two methods of anaesthesia in $\mathbf{4 0}$ patients. Plasma adrenaline and noradrenaline, heart rate, blood pressure, pain and anxiety were documented before and after local anaesthesia and during surgery. There were no statistically significant differences between the responses of the two groups. Both groups demonstrated a statistically significant rise in plasma adrenaline and heart rate. However, this change was minimal compared with the effects reported after severe stress or general anaesthesia, emphasising the importance of allaying patient anxiety during local anaesthesia. We have therefore shown that the larger volume of extraconal orbital anaesthetic solution with the peribulbar technique produces no greater risk of systemic pressor effects.
\end{abstract}

Retrobulbar anaesthesia was first described by Knapp in $1884^{1}$ and remains the commonest form of local anaesthesia practised in the $\mathrm{UK}^{2,3}$ and USA ${ }^{4}$ for cataract surgery. It is, however, not without the risk of serious local and systemic complications. Locally there may be retrobulbar haemorrhage, penetration of the optic nerve or ophthalmic artery and perforation of the globe. ${ }^{5-7}$ More serious are the reported systemic side-effects of grand mal seizures and cardiopulmonary or respiratory arrest. ${ }^{5,7,8}$ The basis of these systemic side-effects remains uncertain. It is thought that with the longer retrobulbar needle,

From: Department of Ophthalmology, Ninewells Hospital, Dundee DD1 9SY, UK.

Correspondence to: Dr R. Sanders, Queen Margaret Hospital, Whitefield Road, Dunfermline KY12 0SU, UK. anaesthetic solution may gain direct entry intracranially by injection through the superior orbital fissure or penetration of the optic nerve sheath. In other cases there may be inadvertent intravenous or intraarterial injection.?

Other methods of local anaesthesia have evolved in an attempt to overcome these potentially serious complications associated with retrobulbar anaesthesia. Peribulbar anaesthesia, administered using a shorter needle, outside the muscle cone, would seem less likely to cause these serious complications. ${ }^{5}$ However, in peribulbar anaesthesia a much larger volume of anaesthetic solution is injected into the extraconal orbit, raising the possibility of increased risk of systemic toxicity. ${ }^{9,10}$

Wittpenn et al. believe that it is the volume of anaesthetic solution and not intravascular or central nervous system injection that causes respiratory arrest. ${ }^{11}$ Ropo et al. ${ }^{12}$ demonstrated that following a peribulbar injection contrast medium could be identified as early as 2 minutes after the injection in the muscle cone. ${ }^{12}$ Zahl et al. ${ }^{13}$ have demonstrated that there is central spread of anaesthetic solution with peribulbar anaesthesia. ${ }^{13}$

To resolve this issue we carried out a prospective randomised comparison of the plasma catecholamine and pressor effects associated with peribulbar and retrobulbar anaesthesia.

\section{PATIENTS AND METHODS}

The study group consisted of 40 patients none of whom had previously had ophthalmic surgery or significant ophthalmic disease. All subjects were randomised to undergo peribulbar or retrobulbar anaesthesia and all had uncomplicated extracapsular cataract surgery with posterior chamber lens implantation. All local anaesthesia and surgery was performed by one of two experienced surgeons.

All patients received $10 \mathrm{ml}$ lignocaine $2 \%$ with 1:200 000 adrenaline and 1500 IU hyalase (one

Eye (1997) 11, 644-648 C 1997 Royal College of Ophthalmologists 


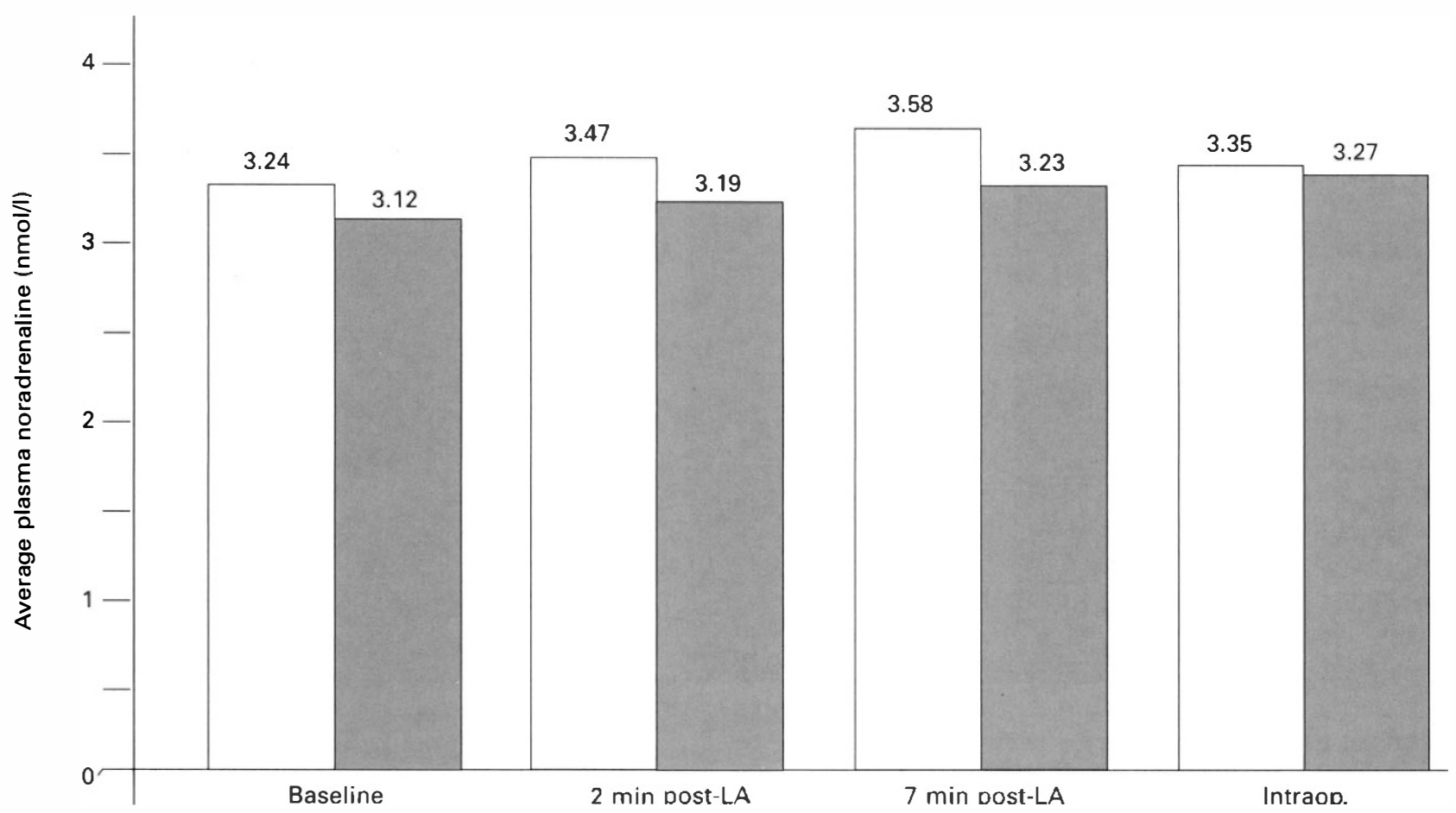

Fig. 1. There was no significant change in plasma noradrenaline throughout the study in either group $(\mathrm{p}=0.839)$. Open columns, peribulbar anaesthesia; grey columns, retrobulbar anaesthesia. LA, local anaesthetic.

ampoule). Peribulbar anaesthesia was administered using a $25 \mathrm{~mm}$ needle. Four millilitres was injected into the supratrochlear space and $6 \mathrm{ml}$ into the inferotemporal space. Retrobulbar anaesthesia was administered using a $40 \mathrm{~mm}$ needle. Three millilitres was injected into the retrobulbar space and $7 \mathrm{ml}$ was given as a facial block, as described by O'Brien.

All patients had a venous sample withdrawn and heart rate and systemic blood pressure measured before administration of the local anaesthetic, 2 and 7 minutes after local anaesthesia and just after extraction of the cataract. At these times levels of anxiety and pain were documented. Anxiety and pain were graded as 0 (none), 1 (mild), 2 (moderate) or 3 (severe). The venous samples were used to measure plasma adrenaline and noradrenaline levels using high-performance liquid chromatography. ${ }^{14}$ All patients were given a patient information sheet and consent for the study was obtained from the local medical ethics committee.

\section{RESULTS}

There was no significant difference in sex, age, weight or duration of time from administration of local anaesthesia to extraction of the cataract, between the two groups of 20 patients who underwent retrobulbar or peribulbar anaesthesia. Coexisting diseases, medication and social habits such as

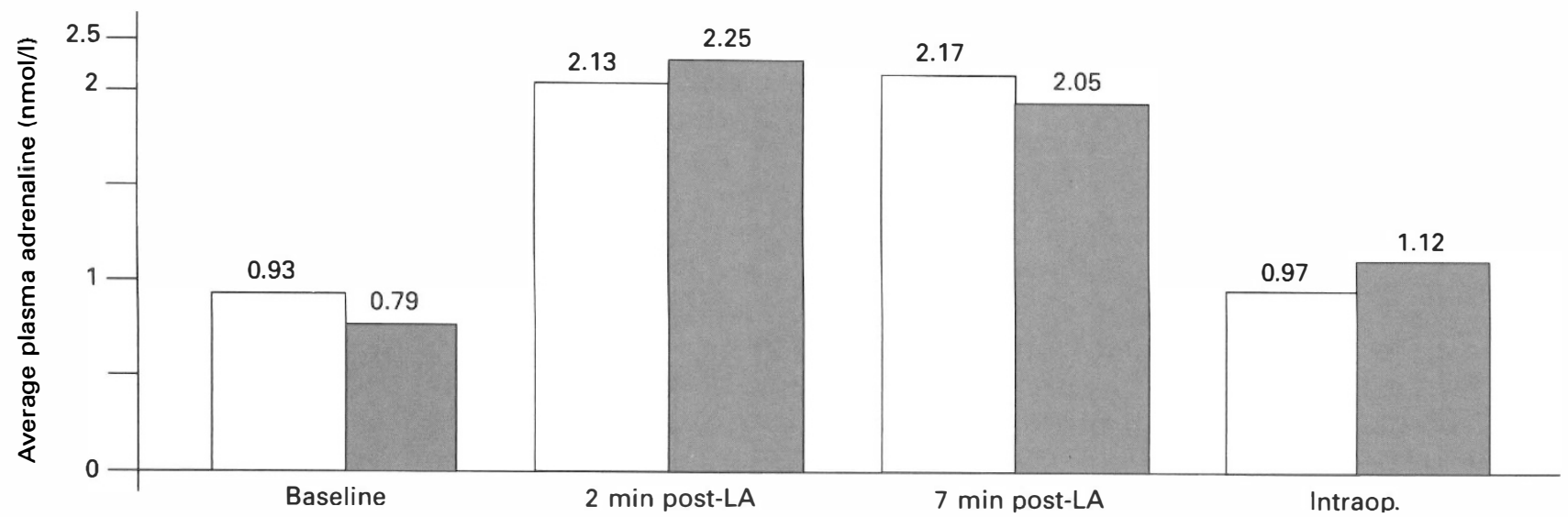

Fig. 2. There was a similar, significant rise in plasma adrenaline in both groups $(\mathrm{p}=0.001)$. Open columns, peribulbar anaesthesia; grey columns, retrobulbar anaesthesia. 


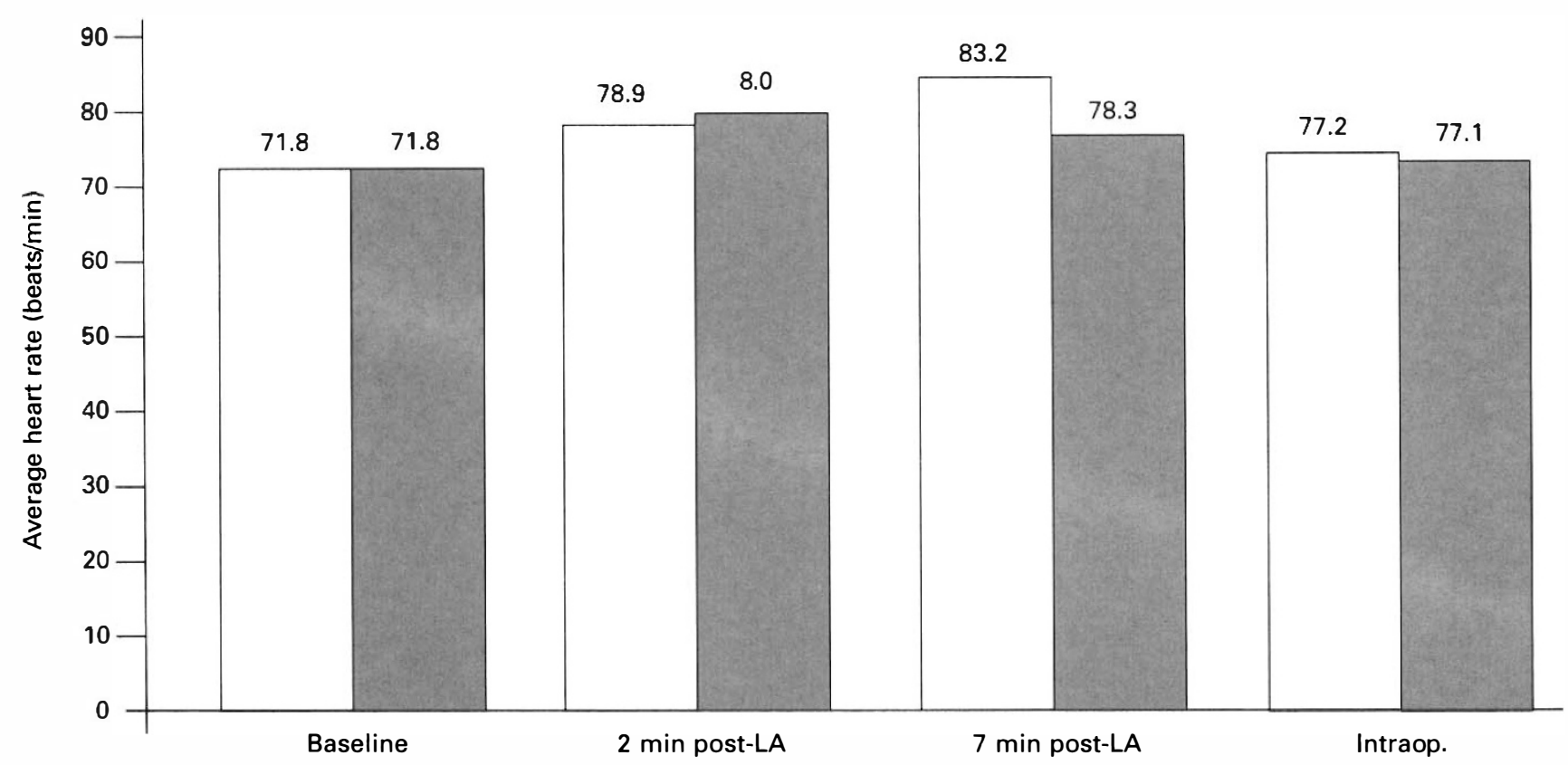

Fig. 3. There was a similar significant rise in heart rate in both groups $(\mathrm{p}=0.001)$. Open columns, peribulbar anaesthesia; grey columns, retrobulbar anaesthesia.

smoking that may alter patients' responses to surgery (particularly with regard to catecholamine and cardiovascular responses) showed a fairly even distribution between the two groups of patients.

Analysis of variance was used to compare plasma adrenaline, noradrenaline, heart rate and blood pressure between the peribulbar and retrobulbar group. There was no significant change in plasma noradrenaline levels throughout the study period in either group $(p=0.836)$. There was also no overall difference between the two groups $(p=0.637)$ and no difference comparing the time trend between the groups $(p=0.674)$. The range of plasma noradrenaline recorded in the peribulbar group was $0.95-8.34 \mathrm{nmol} / 1$ and in the retrobulbar group $0.95-8.20 \mathrm{nmol} / \mathrm{l}$ (Fig. 1).
There was a similar significant rise in both groups in plasma adrenaline levels 2 and 7 minutes after the local anaesthetic injection, settling to baseline levels during surgery $(p=0.001)$. There was no overall difference between the groups $(p=0.924)$ and no difference comparing time trend between groups $(p=0.807)$. The range of plasma adrenaline recorded in the peribulbar group was $0.14-5.08$ $\mathrm{nmol} / \mathrm{l}$ and in the retrobulbar group $0.23-4.21 \mathrm{nmol}$ (Fig. 2).

There was a similar significant rise in heart rate in both groups after the local anaesthetic injection and this was maintained throughout surgery $(p<0.001)$. There was no overall difference between the groups $(p=0.932)$ and no difference comparing the time trend between the groups $(p=0.289)$. Heart rate ranged from 42 to 118 beats per minute in the

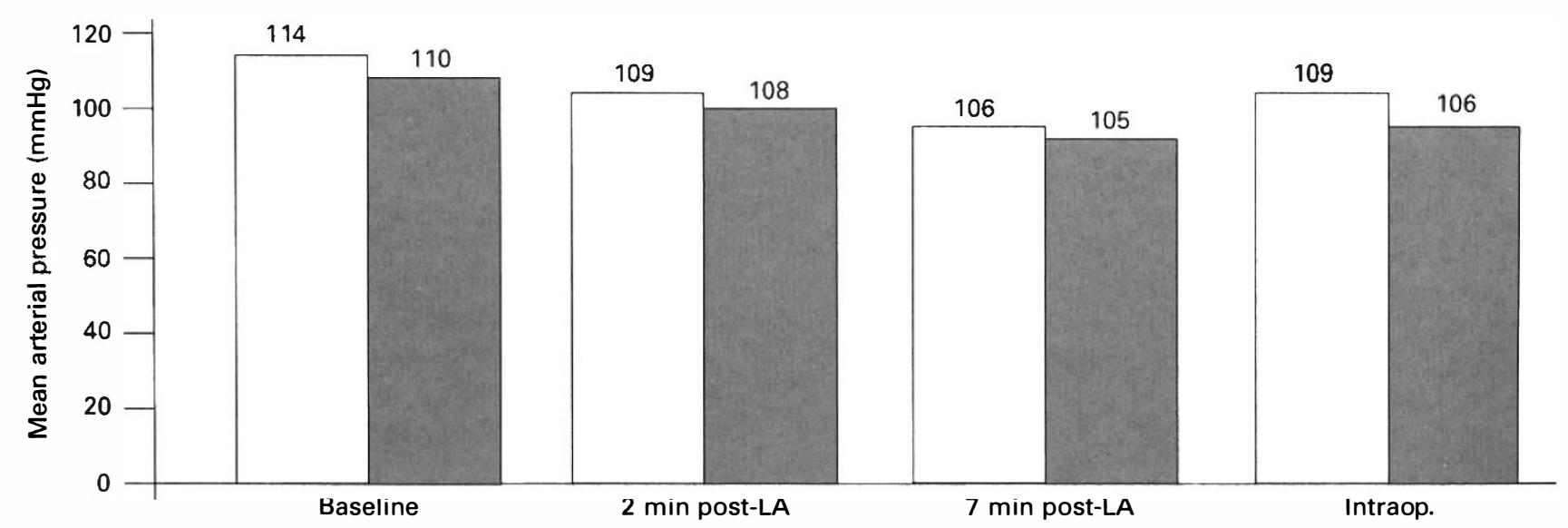

Fig. 4. Mean arterial pressure was significantly higher in both groups before local anaesthesia $(\mathrm{p}=0.009)$. Open columns, peribulbar anaesthesia; grey columns, retrobulbar anaesthesia. 
Table I. Most patients in both groups admitted to little or no pain following local anaesthesia

\begin{tabular}{|c|c|c|c|c|c|c|}
\hline \multirow[b]{2}{*}{ Grades of pain } & \multicolumn{3}{|c|}{ Peribulbar (20 patients) } & \multicolumn{3}{|c|}{ Retrobulbar (20 patients) } \\
\hline & 2 min post-LA & 7 min post-LA & Intraoperatively & 2 min post-LA & 7 min post-LA & Intraoperatively \\
\hline 0 (none & 15 & 20 & 18 & 17 & 20 & 18 \\
\hline 1 (mild) & 2 & 0 & 1 & 2 & 0 & 2 \\
\hline 2 (moderate) & 3 & 0 & 1 & 1 & 0 & 0 \\
\hline 3 (severe) & 0 & 0 & 0 & 0 & 0 & 0 \\
\hline
\end{tabular}

LA, local anaesthetic.

peribulbar group and from 52 to 116 beats per minute in the retrobulbar group (Fig. 3).

Mean arterial pressure was significantly higher in each group before the local anaesthetic injection $(p=0.009)$. Overall there was no significant difference between the groups $(p=0.596)$ and no difference comparing the time trend between groups $(p=0.808)$. Mean arterial pressure ranged from 87 to $127 \mathrm{mmHg}$ in the peribulbar group and 70 to $145 \mathrm{mmHg}$ in the retrobulbar group (Fig. 4).

Most patients in both groups had grade 0 or 1 of anxiety before the local anaesthetic injection. After the local anaesthetic injection most patients in both groups admitted to grade 0 or 1 of pain. The few that admittéd to severe anxiety showed no corresponding rise in plasma catecholamine levels (Table I).

\section{DISCUSSION}

We have shown that peribulbar anaesthesia which involves the injection of a large volume of anaesthetic solution in the extraconal orbit does not produce any greater plasma catecholamine or pressor effects than retrobulbar anaesthesia. In our study there was a similar, short-lived rise in plasma adrenaline with both peribulbar and retrobulbar anaesthesia. This was not accompanied by a corresponding rise in plasma noradrenaline, and therefore must be the result of absorption of adrenaline into the systemic circulation from the local anaesthetic injection.

Diluted adrenaline is included in local anaesthetic solutions as it limits systemic absorption, allowing a greater amount of anaesthetic solution to be given without toxicity. ${ }^{15,16}$ The systemic toxic effects of adrenaline are anxiety, palpitations, tachycardia, hypertension and tachypnoea, ${ }^{15,16}$ and some are of the opinion that it should be avoided in patients with ischaemic heart disease, hypertension, diabetes or thyroid disease. Because of its cardiovascular effects the maximum dose of adrenaline recommended for use in local anaesthesia is $40 \mathrm{ml}$ of 1:200 000 solution, which is 4 times the dose used in our study. ${ }^{17}$

The potential side-effects of lignocaine are cardiac arrhythmias, cardiovascular collapse and respiratory arrest. ${ }^{11}$ The maximum safe dose of lignocaine $2 \%$ with adrenaline is $25 \mathrm{ml},{ }^{15,16}$ which is 2.5 times the dose used in our study.

Heart rate showed a minimal, though significant, rise in both groups following local anaesthesia. Since this rise was sustained intraoperatively, even after plasma adrenaline levels returned to normal, we do not believe this to be the result of plasma catecholamines.

Surprisingly blood pressure was highest in both groups before local anaesthesia, lending further evidence to the fact that the local anaesthetic injection in our study did not give rise to untoward cardiovascular effects. We believe that anxiety before local anaesthesia accounts for this rise in blood pressure.

Most patients were comfortable in both groups of anaesthesia, admitting to mild degrees of anxiety and pain. Even the few that admitted to severe anxiety or pain showed no corresponding rise in plasma catecholamine levels.

Other studies have shown that severe stress ${ }^{18}$ and general anaesthesia ${ }^{19}$ in cataract surgery lead to far higher rises in plasma catecholamine levels, with labile cardiovascular effects, than that associated with local anaesthesia. These studies and our study lend indirect evidence that an endogenous sympathoadrenal response remains the most potent source of catecholamines. Allaying anxiety with careful explanation should take high priority before and during local anaesthesia cataract surgery. Individual patient variability and general health should also be taken into account as, for example, it has been shown that both hypoxia and hypercapnia compound local anaesthesia toxicity. 8,16

Key words: Anaesthesia, Cataract surgery, Catecholamines, Peribulbar, Pressor effects, Retrobulbar.

\section{REFERENCES}

1. Knapp H. On cocaine and its use in ophthalmic and general surgery. Arch Ophthalmol 1884;13:402-48.

2. Hodgkins PR, Luff AJ, Morell AJ, et al. Current practice of cataract extraction and anaesthesia. $\mathrm{Br} \mathbf{J}$ Ophthalmol 1992;76:323-6.

3. Campbell DN, Spalton DJ. National survey of the use of local anaesthesia for cataract surgery. Eur J Implant Ref Surg 1992;4:213-7.

4. Oliver D, Bass EB, Sharkey P. Cataract surgical techniques. Arch Ophthalmol 1995;113:1108-12.

5. Weiss JL, Deichman CB. A comparison of retrobulbar and periocular anaesthesia for cataract surgery. Arch Ophthalmol 1989;107:96-8.

6. Horton JC. Confirmation by magnetic resonance imaging of optic nerve injury after retrobulbar anaesthesia. Arch Ophthalmol 1996;114:351-3. 
7. Feibel RM. Current concepts of retrobulbar anaesthesia. Surv Ophthalmol 1985;30:102-10.

8. Jayamanne DGR, Gillie RF. The effectiveness of perioperative cardiac monitoring and pulse oximetry. Eye 1996;10:130-2.

9. Bruck LB. Needle could reduce retrobulbar risks. Ophthalmol Times 1988;13:1,21.

10. Rubin AP. Local anaesthesia for ophthalmic surgery: an anaesthetist's view. Eur J Implant Ref Surg 1993; 5:8-11.

11. Wittpenn JR, Rapoza P, Sternberg P, et al. Respiratory arrest following retrobulbar anaesthesia. Ophthalmology 1986;93:867-70.

12. Ropo A, Nikki P, Ruusuvaara P, Kivisaari L. Comparison of retrobulbar and periocular injections of lignocaine by computerised tomography. Br J Ophthalmol 1991;75:417-20.

13. Zahl K, Nassif JM, Meltzer MA, Som P. Simulated peribulbar injection of anesthetic. Ann Ophthalmol 1991;23:114-7.
14. Bartlett WA. Biochemical applications. J Chromatogr 1989;493:1-14.

15. Lim AS, Chee CKL. Local anaesthesia in ophthalmology. Curr Anaesth Crit Care 1991;2:117-21.

16. Londsdale M, Buckley JR, Macrae WA. Local anaesthesia for the non-anaesthetist. Hospital Update 1991;[March]:229-36.

17. Henslee TM, Hodson SB, Lamy CJ, Palladino SJ. Vasoconstrictive agents commonly used in combination with local anaesthetics: a literature review. J Foot Surg 1987;26:504-10.

18. Donlon JV, Moss J. Plasma catecholamine levels during local anesthesia for cataract operations. Anesthesiology 1979;51:471-3.

19. Barker JP, Vafidis GC, Robinson PN, Hall GM. Plasma catecholamine response to cataract surgery: a comparison between general and local anaesthesia. Anaesthesia 1991;46:642-5. 